\title{
Investigating the utilisation of ERP systems in the UAE
}

\author{
Samar Mouakket \\ College of Business Administration, \\ Management Information Systems Department, \\ University of Sharjah, \\ P.O. Box 27272, Sharjah, UAE \\ E-mail: samar@sharjah.ac.ae
}

\begin{abstract}
Enterprise resource planning (ERP) systems have changed the way organisations process their information, yet limited research has been conducted to investigate employees' utilisation of ERP systems. This research proposes a model that integrates the technology acceptance model (TAM) with the task-technology fit (TTF) model to investigate ERP systems usage. An empirical study was conducted to analyse the data. The data were analysed using structural equation modelling (SEM) techniques to evaluate the strength of the hypothesised relationships. The results strongly support the extended TAM in predicating employees' utilisation of ERP systems. This research also finds that the TTF model is a valuable addition to TAM for ERP systems tasks. The results and the implications of the findings are discussed in the study.
\end{abstract}

Keywords: technology acceptance model; TAM; information systems; IS; task-technology fit; TTF; enterprise resource planning; ERP; United Arab Emirates; UAE.

Reference to this paper should be made as follows: Mouakket, S. (2012) 'Investigating the utilisation of ERP systems in the UAE', Int. J. Internet and Enterprise Management, Vol. 8, No. 1, pp.46-65.

Biographical notes: Samar Mouakket is an Associate Professor in the MIS Department at the University of Sharjah, UAE. She received her PhD in 1996 in Management IS from Sheffield University, UK. Her research interests include systems analysis and user requirements determination during systems development, geographic information systems, data analysis (OLAP and data mining). She has also research interest in the deployment and utilisation of different business IS, such as ERP systems, as well as web-based business applications, such as ecommerce, e-learning, e-government and e-banking.

\section{Introduction}

Enterprise resource planning (ERP) systems have changed the way organisations process their information. Instead of having several separate information systems (ISs), organisations can install integrated IS. In other words, ERP systems consist of several software packages, such as human resources, sales, finance and production, which allow for cross-organisation integration of data (Esteves and Pastor, 2001; Haines and Goodhue, 2003; Shih, 2006). These software packages can be customised to fit the needs 
of an organisation. Although there has been disagreement on the definition of ERP systems (Klaus et al., 2000), they all share certain characteristics. One important feature is a high level of integration with all applications sharing a single database (Smyth, 2001). In addition, ERP systems are designed for an online client/server environment, with a high level of application functionality and richness which can be customised to fit the needs of the individual customer (Smyth, 2001). Currently, SAP, Oracle, PeopleSoft, Baan and J.D. Edwards are considered the top ERP vendors. Overall, ERP systems can benefit organisations in many ways. Firstly, they can provide support for all variations of best business practices. Secondly, they enable the implementation of these practices with the aim of improving productivity and operational performance. Finally, they enable organisations to modify the implemented business processes to fit their requirements (Holland et al., 1999; Rao, 2000; Chang et al., 2008; Madapusi and D’Souza, 2012).

Yet, despite these advantages, ERP systems are considered very costly and often require disruptive organisational changes to implement (Soh et al., 2000; Wu and Wang, 2006; Osei-Bryson et al., 2008; Sun et al., 2009; Tsai et al., 2011). Moreover, ERP systems implementation is complex, involving technology improvement and change management. While some researchers suggest that ERP implementation failure rates exceed $50 \%$, others have anticipated that about $75 \%$ of the implemented ERP systems are unsuccessful (Bagchi et al., 2003; Rolland and Prakash, 2000; Barker and Frolick, 2003; Brown, 2004; Holsapple and Sena, 2005; Yeh et al., 2007).

Researchers have developed different models to study users' perception and utilisation of IS. Two of the most adopted models are the technology acceptance model (TAM) (Davis, 1989) and the task-technology fit (TTF) model (Goodhue and Thompson, 1995). While the TAM is concerned with predicting IS acceptance and usage behaviour (Davis, 1989), the TTF model focuses on the ability of the IS to support users' tasks (Dishaw and Strong, 1999). But few studies have integrated the two models or added additional constructs to the combined models to better explain users' perceptions of IS (Dishaw and Strong, 1999; Dishaw et al., 2002; Klopping and McKinney, 2004; Sun et al., 2007; Zhang et al., 2007; Wu et al., 2007; Chang et al., 2008; Usoro et al., 2010). The result of combining the two models provides a better model of IS adoption than either an attitude or a fit model provided separately (Dishaw and Strong, 1999; Usoro et al., 2010). In other words, combining the two models enables the capturing of two different aspects of users' choice to utilise IS (Dishaw et al., 2002; Klopping and McKinney, 2004).

In this paper, we follow this line of research by developing and evaluating an integrated TAM/TTF model to understand employees' attitudes towards ERP systems utilisation in the United Arab Emirates (UAE). Specifically, we have adapted the Klopping and McKinney (2004) integrated model, which combined the TAM with the TTF model to evaluate online shopping activities, to study ERP systems utilisation. We aim at examining significant variables' correlation and predictive influence on ERP utilisation construct. We believe that one should not only consider beliefs about perceived usefulness (PU) and perceived ease of use (PEOU) when investigating employees' perceptions of ERP systems utilisation, but also the extent to which ERP systems activities meet employee task needs.

Given that ERP systems have received little academic IS research attention, although the rate of ERP implementation failure has been rather high (Amoako-Gyampah and Salam, 2004; Chang et al., 2008; Bueno and Salmeron, 2008; Youngberg et al., 2009), we feel that research into employees' utilisation of this pioneering technology is of great 
interest to different stakeholders. In addition, most published research conducted on ERP systems has been undertaken in America and western countries with very limited knowledge of ERP system utilisation in the Gulf region, particularly in the UAE.

Although many organisations have implemented ERP systems in the UAE to obtain the expected benefits, there is a lack of research examining the extent of these benefits. In fact, although UAE is considered one of the fastest growing countries in the region with strong information technology (IT) infrastructure, to date there is little information on ERP systems utilisation in the UAE, the obstacles facing its utilisation and the factors affecting its utilisation. A review of the literature has revealed that only very few and recent studies have been conducted on ERP systems in the UAE (Albadri and Abdallah, 2009; Gamal, 2009). Therefore, we feel that our research will contribute to the body of knowledge about this technology and provide some insights about the utilisation of ERP systems, particularly in the UAE.

The rest of the paper is divided as follows: Section 2 contains a literature review of the application of the TAM and the TTF model. Section 3 presents the conceptual model and hypotheses development. Section 4 introduces the research methodology to be used, the analysis of the data collected and the results reached. The data have been analysed using structural equation modelling (SEM) to evaluate the strength of the hypothesised relationships. Section 5 consists of the discussion and the implications of the research and finally Section 6 discusses the limitations of the study and provides suggestions for further research.

\section{Literature review}

Before presenting our proposed model, we review the literature on the application of the TAM and the TTF model towards IS users' behaviour in general and ERP systems in particular.

\subsection{Technology acceptance model}

The TAM is an adaptation of the theory of reasoned action (TRA) (Fishbein and Ajzen, 1975) but with more emphasis on user acceptance of IS. It was developed to explain and predict IS usage behaviour (Davis, 1989) and has been considered a rigorous and valuable model when studying user acceptance of a new IT (Mathieson, 1991; Adams et al., 1992; Taylor and Todd, 1995; Venkatesh, 2000). The TAM is considered a prominent theoretical model for examining the factors contributing to the acceptance of new information technologies, thus it is considered one of the most frequently cited and universally applied models for explaining individuals' attitudes towards an IS (Lee et al., 2003; King and He, 2006).

The TAM hypothesises that an individual's acceptance of an IS is determined by an individual's intentions to use that technology which then leads to actual technology usage. The intention is determined by two beliefs dealing with

1 the PU of using the new IS

2 the PEOU of the new IS (Davis, 1989). 
The PU is related to the degree to which a person believes that using a specific IS will increase his/her job performance and PEOU is the degree to which the user expects a specific system to be easy to use. The TAM hypothesises that PEOU influences behavioural intention both directly and through its effect on PU (Davis et al., 1989). In addition, evidence has shown that both PEOU and PU have an influence on user attitude towards IS acceptance (Davis et al., 1989; Venkatesh and Davis, 1996).

But PEOU and PU are also influenced by exogenous variables, which vary according to the context. Davis (1989) has pointed out that further research is needed to address how other variables can affect PEOU and PU. Exogenous variables can be added to the TAM as a way of improving the original model (Davis et al., 1989; Davis, 1993; Taylor and Todd, 1995). A key aspect of the TAM, therefore, is to provide a basis for investigating the influence of exogenous factors on endogenous factors of attitudes towards an IS.

Within the context of our study, many researchers have applied the TAM to investigate ERP systems applications in organisations (Nah et al., 2004; Amoako-Gyampah, 2007; Wu and Wang, 2006; Youngberg et al., 2009). Bueno and Salmeron (2008) have tested the influence of the following critical success factors (CSF) on ERP implementation: top management support, communication, cooperation, training and technological complexity. They have found that the proposed CSFs have significant influence on ERP implementation. The study by Youngberg et al. (2009) has examined technology acceptance variables for highly educated, professional users of an ERP component to understand significant variables' correlation and predictive effects on PU and usage constructs. They have found that job relevance, output quality and PEOU influence users' perception of technology usefulness.

Nah et al. (2004) have conducted a single-site survey of 229 users of a Midwestern US public institution after its implementation of SAP. The researchers have investigated the effect of perceived fit and perceived compatibility on PU and PEOU. Nah et al. (2004) have also replaced the original TAM 'behavioural intention' construct with 'symbolic adoption' as the primary variable for assessing users' acceptance of ERP systems. They have found the new constructs, perceived fit and perceived compatibility, to have significant effect on attitude toward system use. Also, the researchers have found that symbolic adoption has a significant influence on PEOU, perceived compatibility and attitude toward system use.

Amoako-Gyampah and Salam (2004) have studied the influence of two well-known success factors (training and project communication) on the TAM through a belief construct (shared beliefs in the benefits of an ERP system). The survey was administered at a healthcare products company which has been implementing several modules of SAP software. They have found strong support that communication and training have significant influence on shared beliefs that the users form about the benefits of ERP systems. In addition, they have noted that shared beliefs influence PU and PEOU of the ERP systems. They have concluded that managers should undertake communication and training initiatives to support ERP implementations.

Hwang (2005) has investigated the influence of informal controls, such as cultural control and self-control, on ease of use and usefulness in the adoption and implementation of ERP systems. Uncertainty avoidance was used as a measure for cultural control and perceived enjoyment as a measure for self-control. Hwang found that uncertainty avoidance is strongly related to ease of use and perceived enjoyment has a significant relationship to both ease of use and usefulness. Hwang recommends that 
informal controls need to be considered in ERP implementations as an important managerial tool.

\subsection{TTF model}

The TTF model postulates that a specific technology will be used if the functions available to the user support or fit the activities of the user, thus, IS that do not offer sufficient advantage will not be used by the users (Goodhue, 1995). The TTF model assumes that an individual chooses to use a specific technology that provides benefits, such as improved job performance, regardless of an individual's attitude toward this technology (Goodhue and Thompson, 1995). Irick (2008) believes that TTF plays a key role in affecting individual impact and performance in the use of IS. The TTF model has four main constructs: task characteristics, technology characteristics, utilisation and performance. Task characteristics and technology characteristics together affect the TTF construct, which in turn affects the outcome variable. The heart of the TTF model is a construct known as TTF, which is the matching of the capabilities of a specific technology to the user's task, that is, the ability of an IS to support a specific task (Goodhue and Thompson, 1995). The TTF construct measures the following eight factors:

1 quality

2 locatability

3 authorisation

4 compatibility

5 production timeliness

6 systems reliability

7 ease of use

8 relationship with users.

There has been a number of different studies which adopted the TTF model, such as the evaluation of IS (Goodhue, 1998), the procurement of electronic commerce (Benslimane et al., 2002), the evaluation of the performance of the World Wide Web as an information resource in the domain of international travel (D'Ambra and Wilson, 2004a), the evaluation of the performance of the World Wide Web as an information resource in a specific information domain (D'Ambra and Wilson, 2004b), the investigation of managing virtual teams that manage a majority of their interactions through information and communication technologies (Maruping and Agarwal, 2004), the utilisation of software choices of users (Strong et al., 2006), the evaluation of medical records systems (Kilmon et al., 2008) and mobile banking user adoption (Zhou et al., 2010).

Keil et al. (1995) have found that TTF is more important than the user interface of an IS. In their study, a computer company implemented an expert support system for its sales representatives, but found that usage was low. Feedback indicated that the system was difficult to use, so the company's developers performed a major rewrite of the user interface. After deploying the new and improved tool, they surveyed the users and found that there was no significant increase in use. In addition, the users still perceived the 
software to be cumbersome. Users' comments have shown that the deficiencies were a function of the mismatch between the tasks the system supported and those that the users needed to perform (Keil et al., 1995). The TTF was completely ignored, which meant that the system had no value to the users. Im and Raven (2003) have studied the effects of knowledge management systems (KMS) on individual and organisational performance. They have proposed a model which takes the special characteristics of KMS into account and extends the theory of TTF with concepts from adaptive structuration theory.

In the context of ERP systems, very few studies have applied the TTF model. Smyth (2001) has applied a case study research involving users of a specific ERP system, namely SAP. His results show the value of the TTF construct as an indicator of ERP success. Smyth (2001) has developed a model to examine the impact of information presentation formats on the relationship between information quality and decision quality in an ERP environment. Sun et al. (2009) have integrated prior IS usage research with TTF to propose relationships linking the work context to IS usage and then, to link IS usage back to individual performance in organisations. They have surveyed 138 ERP users in 62 organisations across ten provinces in China to investigate the role of IS usage through perceived work compatibility, which is one dimension of TTF. They believe that perceived work compatibility of ERP systems can be a valuable tool in evaluating the extent to which a company's internal operations and processes are consistent with the rest of the industry.

\section{Conceptual model and hypotheses development}

\subsection{Research model}

The proposed model in this study is a combination of two well-known models in IS, namely the TTF model and the TAM with the aim of determining employees' utilisation of ERP systems in the UAE. Dishaw and Strong (1999) have found that TTF is somewhat more effective than the TAM for predicting use in work-related tasks. However, their study also concluded that a combination of TTF and the TAM into one extended model is a superior model to either the TAM or the TTF model alone. Figure 1 represents the proposed framework.

Figure 1 The proposed research model combined the TAM with the TTF model

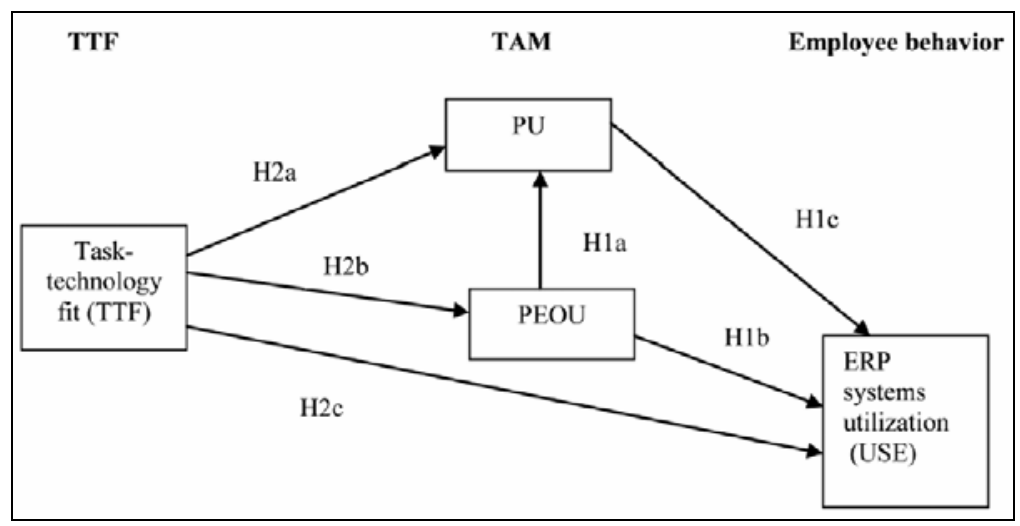




\subsection{Hypotheses}

Based on the TAM, Davis (1989) has shown that IS usage is determined by two beliefs dealing with

1 the PU of using the new IS

2 the PEOU of the IS.

According to our model, both PU and PEOU will influence the actual utilisation of ERP systems. Also, as suggested by previous research (Davis et al., 1989; Venkatesh and Davis, 2000; Venkatesh, 2000) we believe that PEOU is a direct determinant of PU. Therefore, the following hypotheses are proposed:

Hypothesis 1 TAM predicts actual utilisation of ERP systems.

As suggested by the TAM, PEOU is seen to have a significant direct effect on PU and attitude (Davis et al., 1989; Venkatesh and Davis, 2000) and that both PEOU and PU have an influence on user attitude towards IS acceptance (Davis et al., 1989; Venkatesh and Davis, 1996; Venkatesh and Morris, 2000). Thus, the current research investigates the following hypotheses:

Hypothesis H1a PEOU is positively related to PU.

Hypothesis H1b PEOU is positively related to actual utilisation of ERP systems.

Hypothesis H1c PU is positively related to the actual utilisation of ERP systems.

In our model, the TTF model extends the TAM by considering how the task affects the utilisation of ERP systems. A construct called TTF affects the predecessors of ERP systems utilisation in the TAM, namely PEOU and PU. We also suggest that the TTF construct directly affects the ERP systems utilisation. Therefore, the following hypotheses are proposed:

Hypothesis 2 The combined TTF/TAM predicts the actual utilisation of ERP systems.

Several studies have added the TTF model to the TAM to investigate user attitude towards various information technologies. Klopping and McKinney (2004) have extended the TTF model with TAM to predict e-commerce adoption by consumers and have found that the TTF model is a valuable addition to TAM for online shopping tasks. Their findings show that the combined model explains more of the variance of the intention to use. Dishaw and Strong (1999) and later Dishaw et al. (2002) propose a model combining TTF model and TAM with computer self-efficacy to investigate students' perceptions of different software tools. Chang (2008) combines TTF model with TAM to investigate how the fit between the general attributes of intelligent agent's technology characteristics and online auctions' task characteristics affects user intention to use online auction websites. Similarly, Chang (2010) explores the acceptance of intelligent agents to investigate the automation of auction websites within the TTF and the TAM models. Both studies (Chang, 2008, 2010) have revealed that TTF is positively associated with PEOU and PU. Yen et al. (2010) combines both TAM with TTF model to investigate the determinants of users' intention to use wireless technology in organisations. One of their results indicates that TTF has no significant impact on either 
and PEOU and usefulness. Similarly, Dishaw and Strong (1999) suggest that PEOU, but not PU, is affected by TTF.

In recent studies, Shih and Chen (2011) examine the behavioural intention for mobile commerce by integrating TAM with TTF. Their results confirm that the integrated model provides greater explanatory power than either TAM or TTF alone. Polancic et al. (2011) have found that TTF has significant influence on PU as a result of their investigation of different factors affecting user continuous intention to use object-oriented frameworks. Kuo and Lee (2011) have integrated the TAM with TTF to examine the adoption of KMS. One of their findings indicates that TTF is a significant predictor of PEOU.

In the context of ERP systems, very few studies have combined the TTF model with TAM to examine the adoption of this sophisticated technology (Smyth, 2001; Sun et al., 2009); hence, the current study hypothesises that:

Hypothesis H2a TTF is positively related to PU.

Hypothesis H2b TTF is positively related to PEOU.

Hypothesis H2c TTF is positively related to the actual utilisation of ERP systems.

\section{Research methodology}

\subsection{Instrument development and subjects}

This research used the survey method to test its hypotheses. A questionnaire consisting of five parts was developed and administered. The questionnaire is composed of 29 questions, unambiguous and easy for respondents to complete. The first part (eight questions), contains demographic data about the employee. The next four parts include 21 items divided as follows: six items are used to measure PEOU, five items are used to measure PU, seven items are used to measure TTF and three items are used to measure employees' utilisation of ERP systems (USE). The TTF construct, in this study, validated the following dimensions: quality of data, locatability of data, production timeliness, authorisation for access of data and systems reliability. A five-point Likert-type scale ranging from one, 'strongly agree', to five, 'strongly disagree', was used to collect data on each of the proposed constructs.

Since the scales to measure PU, PEOU and ERP systems utilisation have been taken from previously validated IS related studies on the TAM (Davis, 1989; Wang et al., 2003; Roca et al., 2006; Al-Somali et al., 2009), they have been assumed to have valid content. Also, the measures of TTF construct have been captured from Goodhue and Thompson (1995) and Klopping and McKinney (2004), who have also established their reliability and validity. The questionnaire items used to measure each construct are presented in Table 1.

The questionnaire was administered by hand to a convenient sample of 550 employees (UAE nationals and non-UAE nationals) in different large-sized, private and public organisations in two major cities in the UAE, namely Dubai and Abu-Dhabi. The study samples targeted organisations which are actually implementing an ERP system. After gaining permission from the officials of the organisations, the questionnaire was distributed by hand on the premises and later was collected also by hand from the employees who filled in the questionnaire. A total of 365 responses were received. After 
eliminating incomplete responses, we selected 344 usable responses as the sample. The final response rate is $62.54 \%$, which is acceptable for research purposes.

Table 1 Summary of measurement scales

\begin{tabular}{|c|c|c|}
\hline Construct & Measures & \\
\hline \multirow[t]{6}{*}{ PEOU } & PEOU1 & Learning to use the ERP systems is easy for me \\
\hline & PEOU2 & It is easy to do what I want to do using the ERP system \\
\hline & PEOU3 & Using the ERP system is clear and understandable \\
\hline & PEOU4 & Interaction with the ERP system is clear and understandable \\
\hline & PEOU5 & It is easy to become skilful at using ERP system \\
\hline & PEOU6 & Using the ERP system is easy \\
\hline \multirow[t]{5}{*}{ PU } & PU1 & Using the ERP system enables me to complete my work more quickly \\
\hline & PU2 & Using the ERP system has made my work easy \\
\hline & PU3 & Using the ERP system saves me time \\
\hline & PU4 & I find using the ERP system useful in my work \\
\hline & PU5 & Using the ERP system has increased my job productivity \\
\hline \multirow[t]{7}{*}{ TTF } & TTF1 & $\begin{array}{l}\text { The data provided in the ERP system is up-to-date and sufficient for } \\
\text { my purposes }\end{array}$ \\
\hline & TTF2 & $\begin{array}{l}\text { The data provided in the ERP system is pretty much what I need to } \\
\text { carry out my tasks }\end{array}$ \\
\hline & TTF3 & It is easy to find what the ERP system maintains on a given subject \\
\hline & TTF4 & $\begin{array}{l}\text { The exact meaning of the data elements is either obvious or easy to find } \\
\text { in the ERP system }\end{array}$ \\
\hline & TTF5 & $\begin{array}{l}\text { Getting authorisation to access data that would be useful in my job is } \\
\text { time consuming and difficult }\end{array}$ \\
\hline & TTF6 & $\begin{array}{l}\text { Regular ERP system activities (such as printed reports) are completed } \\
\text { on time }\end{array}$ \\
\hline & TTF7 & The ERP system I use is subject to frequent problems and crashes \\
\hline \multirow[t]{3}{*}{ USE } & USE1 & I have used the ERP system \\
\hline & USE2 & I strongly recommend the use of the ERP system \\
\hline & USE3 & I will increase my use of the ERP system \\
\hline
\end{tabular}

\subsection{Data analysis and results}

A statistical analysis has been performed to test the relationships between the different research variables using SEM, which is the preferred approach for analysing interactions between multiple independent and dependent variables, such as the ones used in our model. The study first used SPSS to analyse the demographic data and evaluate Cronbach's alpha. Second, the analysis of data was carried out in two stages using SPSS-AMOS. During the first stage, the measurement model was estimated using a confirmatory factor analysis (CFA) to test whether the proposed constructs had satisfactory validation (convergent validity) and reliability (composite reliability). During the second stage, the structural model was calculated to identify the fitness of the data and to test the hypotheses between constructs based on the proposed model. 
Demographic data, with single item questions, were gathered about the participants including gender, nationality, level of education, job category, age, income, type of the ERP system used and type of organisation. Table 2 shows that the percentage of males is slightly higher than females. Male respondents account for $51.2 \%$ of the sample, while female respondents account for $48.8 \%$. The percentage of non-UAE nationals is relatively higher $(64.3 \%$ to $35.7 \%)$ because, according to the latest UAE government statistics, UAE nationals constitute less than $20 \%$ of the total UAE population. The difference between the employees who hold a university degree and those who do not hold a university degree is $58.4 \%$ to $41.6 \% ; 56.4 \%$ of the employees work as managers or administrators while $39.5 \%$ work in technical related jobs and $57.3 \%$ of the employees who participated in this survey are between the ages of 36 and 45 . More than $50 \%$ of the employees who participated in this survey earn between 76,000 and 149,999 Dirham a year (1 Dirham = US \$3.68). The majority of the employees who participated used either SAP $(37.2 \%)$ or Oracle applications $(34.0 \%)$. Finally, the proportion of employees from private companies was higher than that in public institutions $(57.3 \%$ to $42.7 \%)$.

Table 2 Demographic profile of the data

\begin{tabular}{|c|c|c|}
\hline Item & Number & Percentage $(\%)$ \\
\hline \multirow[t]{2}{*}{ Gender } & 176 male & 51.2 \\
\hline & 168 female & 48.8 \\
\hline \multirow[t]{2}{*}{ Nationality } & 123 (UAE national) & 35.7 \\
\hline & 221 (non-UAE national) & 64.3 \\
\hline \multirow[t]{2}{*}{ University degree } & 201 (yes) & 58.4 \\
\hline & 143 (no) & 41.6 \\
\hline \multirow[t]{4}{*}{ Job category } & 106 (managerial) & 30.8 \\
\hline & 88 (administrative) & 25.6 \\
\hline & 136 (technical) & 39.5 \\
\hline & 14 (other) & 4.1 \\
\hline \multirow[t]{5}{*}{ Age } & $4(<25)$ & 1.2 \\
\hline & $112(26-35)$ & 32.5 \\
\hline & $197(36-45)$ & 57.3 \\
\hline & $29(46-55)$ & 8.4 \\
\hline & $2(>55)$ & 0.6 \\
\hline \multirow[t]{5}{*}{ Average yearly income (UAE Dirham) } & $13(<=49,999)$ & 3.8 \\
\hline & $63(50,000-75,999)$ & 18.4 \\
\hline & $120(76,000-99,999)$ & 34.0 \\
\hline & $81(100,000-149,999)$ & 23.6 \\
\hline & $67(>=150,000)$ & 20.2 \\
\hline \multirow[t]{5}{*}{ ERP systems used } & 117 (Oracle applications) & 34.0 \\
\hline & 38 (Microsoft dynamics) & 11.0 \\
\hline & 59 (PeopleSoft) & 17.2 \\
\hline & 128 (SAP) & 37.2 \\
\hline & 2 (Baan) & 0.6 \\
\hline \multirow[t]{2}{*}{ Organisation type } & 147 (public) & 42.7 \\
\hline & 197 (private) & 57.3 \\
\hline
\end{tabular}




\subsubsection{Measurement model results}

To test the hypotheses, CFA using SPSS-AMOS was used Table 3. According to Hair et al. (1998), a factor should have a minimum of two items and each item factor loading should be greater than 0.4. As a result of the CFA, five items have been excluded (one item has been removed from PEOU, two items have been removed from PU and two items have been removed from the TTF construct), which leaves 16 useful items. After dropping five measurement items from the questionnaire due to low factor loadings (less than .40), all latent constructs are greater than .40 (Table 3). The factors have been loaded as follows: five items are used to measure PEOU, three items are used to measure PU, five items are used to measure the construct TTF and finally three items are used to measure USE.

Table 3 CFA (from SPSS-AMOS)

\begin{tabular}{|c|c|c|c|c|}
\hline Item & Factor loading & Composite reliability & Variance extract & Cronbach's $\alpha$ \\
\hline PEOU & & .932 & .736 & 0.776 \\
\hline PEOU1 & .762 & & & \\
\hline PEOU2 & .785 & & & \\
\hline PEOU3 & .723 & & & \\
\hline PEOU4 & .650 & & & \\
\hline PEOU5 & .646 & & & \\
\hline PU & & .938 & .835 & 0.754 \\
\hline PU1 & .871 & & & \\
\hline PU2 & .892 & & & \\
\hline PU3 & .781 & & & \\
\hline TTF & & .927 & .720 & 0.760 \\
\hline TTF1 & .808 & & & \\
\hline TTF2 & .817 & & & \\
\hline TTF3 & .744 & & & \\
\hline TTF4 & .747 & & & \\
\hline TTF5 & .785 & & & \\
\hline USE & & .917 & .786 & 0.757 \\
\hline USE1 & .762 & & & \\
\hline USE2 & .825 & & & \\
\hline USE3 & .745 & & & \\
\hline
\end{tabular}

Note: Items with less than 0.4 loading factor have been removed.

Source: Hair et al. (1998)

The proposed research model was examined by using SQM techniques. We have used several common model-fit measurements to assess the model's overall goodness Table 4. SEM does not offer a statistical test to describe the strength of the model's predications; instead, there are various parameters to be used. In this study, we have used the following measures of model-fit analysis: chi-square/degree of freedom ratio (CMIN/DF), root mean square residual (REMSEA), goodness of fit (GFI), normed fit index (NFI) and comparative fit index (CFI). Within these model-fit measures, the literature provides 
specific guidelines for recommended values to indicate the performance of the model. Chi-square is the traditional measure for evaluating overall model fit and determining the magnitude of discrepancy between the sample and fitted covariance matrices ( $\mathrm{Hu}$ and Bentler, 1999). Although there is no consensus regarding an acceptable ratio for this statistic, recommendations range between 2.0 and 5.0 (Tabachnick and Fidell, 2007; Wheaton et al., 1977; Barrett, 2007). Second, REMSEA, which has been considered in recent years to be one of the most informative fit indices (Diamantopoulos and Siguaw, 2000), is calculated. There has been an agreement among researchers in this field that the cut-off value is between 0.06 (Hu and Bentler, 1999) and 0.07 (Steiger, 2007).

Table 4 Fitness indices for the measurement and the structural models

\begin{tabular}{lccc}
\hline Fit statistics & Recommended value & CFA model & SEM model \\
\hline CMIN/DF & $<=5.0$ & 4.241 & 4.239 \\
GFI & $>0.90$ & .915 & .912 \\
NFI & $>0.90$ & .907 & .906 \\
CFI & $>0.90$ & .909 & .908 \\
RMSEA & $<0.05$ & .04 & .04 \\
\hline
\end{tabular}

Third, GFI has been calculated. A cut-off point of 0.90 has been recommended for the GFI (Shevlin and Miles, 1998). Fourth, the NFI has been calculated. Values for this statistic range between 0 and 1 with Bentler and Bonnet (1980) recommending values greater than 0.90 indicating a good fit. Finally, the CFI has been used to measure comparative model fit. A cut-off criterion of CFI $\geq 0.90$ has been suggested ( $\mathrm{Hu}$ and Bentler, 1999). Today this index is considered one of the most popularly reported fit indices because it is one of the measures least affected by sample size (Fan et al., 1999).

According to Table 4, the value of CMIN/DF (551.446/130) is 4.241, which is acceptable. The value of GFI is .915 , which is above the suggested value of 0.90 . The values of the normalised and the CFI NFI and CFI are .907 and .909, which is above the suggested estimates of 0.90 and the value of RMSEA is 0.04 (the suggested value $<=0.05)$. These statistics indicate an acceptable-fit for the proposed model.

\subsubsection{Instrument reliability and validity}

The convergent validity and reliability of each construct was tested for the measurement model. First, the reliability of the individual scales was measured by applying the Cronbach's alpha. The overall measures are reported in Table 3. There is a general agreement in the literature that a value of 0.7 and above for the Cronbach's alpha is sufficient (Nunnally, 1978; Nunnally and Bernstein, 1994; Hair et al., 1998). Since all of the items had an alpha above the standard guideline of 0.70 , we can conclude that the scales have acceptable reliability. Second, composite reliability for each construct in the measurement model was calculated. The composite reliability of the constructs was above 0.90 , which exceeds the cut-off value of 0.70 Table 3 . A third measure of reliability is the average variance extract, which represents the overall amount of variance in the indicators accounted for by the latent construct (Wu et al., 2007). Higher variance extracted value occurs when the indicators are truly representative of the latent construct (Wu et al., 2007). According to Fornell and Larcker (1981), convergent validity coefficients should be higher than or equal to 0.50 . All convergent validity coefficients 
calculated for all factors in this study are higher than 0.50 , which concludes that all the constructs used in this study are highly reliable Table 3 .

\subsubsection{Structural model results}

A similar set of fit indices have been used to examine the structural model Table 4. First, relative chi-square is calculated. According to Table 4, a relative chi-square fit index, calculated by dividing the chi-square value by the degrees of freedom, is 4.239. GFI, NFI and CFI are greater than 0.9 and RMSEA is less than 0.1. All fit indices are within acceptable limits, suggesting a good fit to the data.

Table 5 provides a summary of the regression weights. To test the statistical significance of the parameter estimates from SEM, the critical ratio (CR) is calculated by dividing the estimate of the covariance by its estimated standard error (SE), which is an estimate of the SE of the covariance. A value exceeding 1.96 represents a level of significance of 0.05 . Below this level, the factor can be considered unimportant to the model (Chau, 1997; Hair et al., 1998). Thus, the results of the SEM analysis show that hypotheses H1a, H1b, H2a and $\mathrm{H} 2 \mathrm{~b}$ have been supported as the significance level less than .001 and $\mathrm{H} 2 \mathrm{c}$ has been supported, as the significance level is less than .01 . Hypothesis H1c has not been supported, as the significance level has been greater than 0.05 (Table 6). Figure 2 shows the standardised regression weights for the proposed model.

Table 5 Summary of regression weights

\begin{tabular}{lcccc}
\hline & Estimate & $S E$ & $C R$ & $P$ \\
\hline PU PEOU & .286 & .075 & 3.813 & $* * *$ \\
USE PEOU & .219 & .059 & 3.711 & $* * *$ \\
USE PU & .066 & .060 & 1.105 & .269 \\
PU TTF & .660 & .098 & 6.744 & $* * *$ \\
PEOU TTF & .589 & .087 & 6.770 & $* * *$ \\
USE TTF & .217 & .074 & 2.932 & .003 \\
\hline
\end{tabular}

Note: $* * *$ Significance at $\mathrm{p}<0.001$

Table 6 Summary of results of the hypothesis testing

\begin{tabular}{lc}
\hline Hypothesis & Result of testing \\
\hline H1a: PEOU is positively related to PU & $\mathrm{S}$ \\
H1b: PEOU is positively related to actual utilisation of ERP systems. & $\mathrm{S}$ \\
H1c: PU is positively related to the actual utilisation of ERP system. & $\mathrm{NS}$ \\
H2a: TTF is positively related to PU. & $\mathrm{S}$ \\
H2b: TTF is positively related to PEOU. & $\mathrm{S}$ \\
H2c: TTF is positively related to the utilisation of ERP systems. & $\mathrm{S}$ \\
\hline
\end{tabular}

Notes: S: supported and NS: not supported 
Figure 2 Summary of standardised regression weights

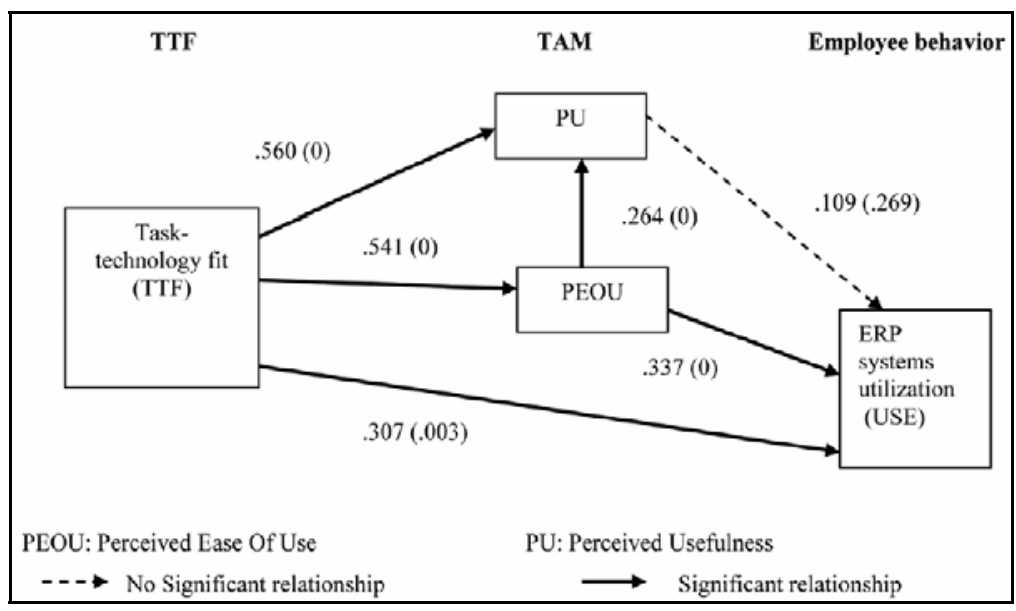

Note: The numbers in brackets indicate values of significance (p-values).

\section{Discussion}

\subsection{Summary of results}

This study has extended previous research by incorporating the TTF model into the TAM to enable the capturing of two different aspects of users' choice to utilise ERP systems. The results of this study show strong support for the use of a modified TAM, which includes TTF and the TAM to understand employee utilisation of ERP systems (Table 6). This study has found that utilisation of ERP systems depends on both task fit and perceptions of ease of use and usefulness of this technology. In the combined model, TTF has a significant effect on PEOU, PU and USE. Thus, we can conclude that the TTF plays a key role in affecting individual utilisation of ERP systems. These findings are similar to those of previous studies (Dishaw and Strong, 1999; Dishaw et al., 2002; Klopping and McKinney, 2004), who have suggested that in a workplace setting, a combined TTF/TAM is better than the TAM alone in predicting IS utilisation. An individual's use of a specific technology that provides benefits will influence the extent of usefulness and ease of use of this technology. In other words, when the degree of fitness between the task and the technology increases, employees perceive the tool to be easier to use and more useful for that task (Wu et al., 2007).

Surprisingly, PU has no significant influence on utilisation of ERP systems. Similar results were obtained from Shih (2006) and Shih and Huang (2009), who have found that PU influences behavioural intention, but does not affect actual usage of ERP systems. This can be attributed to the fact that the use of ERP systems is considered by employees to be mandatory. Thus, employees have no choice but to use this technology regardless of their perceptions of its benefits to them. In an ERP environment users are more concerned with the larger goal of how an ERP system supports their task rather than whether the technology is perceived as useful to them. When the use of a specific technology is mandated in a working environment, a user has no freedom of choice to accept or refuse to use this technology (Brown et al., 2002). In the context of this study, 
we believe that the decision to accept or use the ERP system is usually taken by the management and employees are required to use the ERP system to execute their duties regardless of their feelings as to the extent of its usefulness.

\subsection{Implications and key insights}

The research results of this study have implications for users of ERP systems, software vendors and IS research. The study focuses on the factors affecting ERP systems utilisation in the UAE in companies which have already implemented an ERP system, because we believe that although an ERP system may be successfully implemented, the post-implementation of the systems is where the real challenges will begin and more important risks may occur (Willis and Willis-Brown, 2002; Buonanno et al., 2005). Being aware of these factors can help managers in the UAE to better obtain the full benefits of these complex and costly systems. Some studies have found that systems may suffer underutilisation or intentional sabotage by users (Markus and Keil, 1994; Brown et al., 2002; therefore it is important that managers help their employees to understand how the ERP system fits with the organisation's plans and how to obtain its expected benefits. Several studies have shown the contribution of TTF in ensuring user utilisation of IS (Wells and Palmer, 2004; Dishaw and Strong, 2005), thus, managers who want to ensure total utilisation of ERP systems can organise ERP system training sessions for their employees. During these sessions, managers can encourage employees to discover different ways to improve their work quality by using ERP systems, therefore improving the utilisation of this technology. Also, experience sharing can be provided for new ERP system users to motivate them to understand the benefits of this technology (Roger, 1995).

This study also has implications for IS research, as it provides insights into the ERP market and environment in the UAE. Our findings highlight the need to continue with more research about this topic, which so far has received limited investigation. Organisations spend a lot of money on ERP systems, much of which is underutilised. Thus, this research has provided a better understanding of the factors that help to utilise this important technology. The more individuals find information in the system related to their tasks, the more likely they perceive the system to be useful (Gluck, 1996). If organisations have a better understanding of the extent of ERP systems utilisation by employees, they can take actions to encourage better utilisation of this software. In addition, this study has shown the applicability of a combined TTF/TAM model in understanding employee utilisation of ERP systems in the UAE. It is consistent with previous studies which consider the combination of TTF and the TAM into one extended model to be more valuable than either the TAM or the TTF models alone (Dishaw et al., 2002; Klopping and McKinney, 2004).

Finally, this study is of interest to ERP systems vendors who need to be aware that actual utilisation depends not only on PEOU, but also on how well the tool functionality matches the needs of the task. The results of this study will also help to improve the understanding of ERP satisfaction from an ERP user perspective. Developing a well-designed ERP system that matches the employee task will enable him/her to appreciate this complex technology more easily and effectively. The findings from research suggest that ERP vendors who want to succeed in the UAE should consider the findings of this research and develop better strategies that address the factors suggested in this study before entering the UAE market. 


\section{Limitations and suggestions for future study}

This research has several limitations which need to be considered. The research has used a convenience sampling method. A more detailed study could be carried out to investigate the utilisation of ERP systems, based on a larger sample. Second, we cannot generalise our findings, since our sample may generate results not applicable to employees in other parts of the Gulf region. A longitudinal study to test the model of this study can be valuable. Third, future studies could further extend the combined TAM/TTF model to include other external variables such as computer self-efficacy and ERP systems functionality features.

\section{Acknowledgements}

The author is grateful to the editor and the anonymous reviewers for their constructive comments on an earlier version of the paper, which has helped to improve its quality.

\section{References}

Adams, D.A., Nelson, R.R. and Todd, P.A. (1992) 'Perceived usefulness, ease of use and usage information technology', MIS Quarterly, Vol. 16, No. 2, pp.227-250.

Albadri, F.A. and Abdallah, S. (2009) 'ERP training and evaluation: ERP life-cycle to end-users' characterization and competency building in the context of an oil \& gas company', IBIMA Business Review, Vol. 3, No. 2, pp.19-26.

Al-Somali, S.A., Gholami, R. and Clegg, B. (2009) 'An investigation into the acceptance of online banking in Saudi Arabia', Technovation, Vol. 29, No. 2, pp.130-141, Elsevier.

Amoako-Gyampah, K. (2007) 'Perceived usefulness, user involvement and behavioral intention: an empirical study of ERP implementation', Computer in Human Behavior, Vol. 23, No. 3, pp.1232-1248.

Amoako-Gyampah, K. and Salam, A.F. (2004) 'An extension of the technology acceptance model in an ERP implementation environment', Information and Management, Vol. 41, No. 6, pp.731-745.

Bagchi, S., Kanungo, S. and Dasgupta, S. (2003) 'Modeling use of enterprise resource planning systems: a path analytic study', European Journal of Information Systems, Vol. 12, No. 2, pp.142-158.

Barker, T. and Frolick, M.N. (2003) 'ERP implementation failure: a case study', Information Systems Management, Vol. 4, pp.43-49.

Barrett, P. (2007) 'Structural equation modelling: adjudging model fit', Personality and Individual Differences, Vol. 42, No. 5, pp.815-24.

Benslimane, Y., Plaisent, M. and Bernard, P. (2002) 'Applying the task-technology fit model to WWW-based procurement: conceptualization and measurement', Proceedings of the 36th Hawaii International Conference on Systems Sciences (HUICSS'03), 6-9 January, Island of Hawaii, IEEE Computer Society, USA, pp.561-570.

Bentler, P.M. and Bonnet, D.C. (1980) 'Significance tests and goodness of fit in the analysis of covariance structures', Psychological Bulletin, Vol. 88, No. 3, pp.588-606.

Brown, S.A., Massey, A.P., Montoya-Weiss, M.M. and Burkman, J.R. (2002) 'Do I really have to? user acceptance of mandated technology', European Journal of Information Systems, Vol. 11, No. 4, pp.283-295. 
Brown, W. (2004) 'Enterprise resource planning (ERP) implementation planning and structure: a recipe for ERP success', Proceedings of the 32nd Annual ACM SIGUCCS Conference on User Services, Baltimore, MD, USA, pp.82-86.

Bueno, S. and Salmeron, J.L. (2008) 'TAM-based success modeling in ERP', Interacting with Computer, Vol. 20, No. 6, pp.515-523.

Buonanno, G., Faverio, P., Pigni, F., Ravarini, A., Sciuto, D. and Tagliavini, M. (2005) 'Factors affecting ERP system adoption: a comparative analysis between SMEs and large companies', Journal of Enterprise Information Management, Vol. 18, No. 4, pp.384-426.

Chang, H.H. (2010) 'Task-technology fit and user acceptance of online auction', International Journal of Human-computer Studies, Vol. 68, Nos. 1-2, pp.69-89.

Chang, H-H. (2008) 'Intelligent agent's technology characteristics applied to online auctions task: a combined model of TTF and TAM', Technovation, Vol. 28, No. 9, pp.564-577.

Chang, M-K., Cheung, W., Cheng, C-H. and Yeung, J.H.Y. (2008) 'Understanding ERP system adoption from the user's perspective', International Journal of Production Economics, Vol. 113, No. 2, pp.928-942.

Chau, P.Y.K. (1997) 'Reexamining a model for evaluating information success using a structural equation modeling approach', Decision Sciences, Vol. 28, No. 2, pp.309-335.

D'Ambra, J. and Wilson, C.S. (2004a) 'Use of the World Wide Web for international travel: integrating the construct of uncertainty in information seeking and the task-technology fit (TTF) model', Journal of the American Society for Information Science and Technology, Vol. 55, No. 8, pp.731-742.

D'Ambra, J. and Wilson, C.S. (2004b) 'Explaining perceived performance of the World Wide Web: uncertainty and the task-technology fit model', Internet Research, Vol. 14, No. 4, pp.294-310.

Davis, F.D. (1989) 'Perceived usefulness, perceived ease of use and user acceptance of information technology', MIS Quarterly, Vol. 13, No. 3, pp.319-340.

Davis, F.D. (1993) 'User acceptance of information technology: system characteristics, user perceptions and behavioral impacts', International Journal of Man-Machine Studies, pp.475-487.

Davis, F.D., Bagozzi, R.P. and Warshaw, R.P. (1989) 'User acceptance of computer technology: a comparison of two theoretical models', Management Sciences, Vol. 35, No. 8, pp.982-1003.

Diamantopoulos, A. and Siguaw, J.A. (2000) Introducing LISREL, Sage Publications, London.

Dishaw, M.T. and Strong, D.M. (1999) 'Extending the technology acceptance model with task-technology fit constructs', Information \& Management, Vol. 36, No. 1, pp.9-21.

Dishaw, M.T. and Strong, D.M. (2005) 'Examining multiple dimensions of task-technology fit', Proceedings of the Eleventh Americas Conference on Information Systems, 11-14 August, Omaha, NE, USA.

Dishaw, M.T., Strong, D.M. and Bandy, D.B. (2002) 'Extending the task-technology fit model with self-efficacy constructs', Proceedings in the Eighth Americas Conference on Information Systems, 9-11 August, Dallas, USA, pp.2021-2027.

Esteves, J. and Pastor, J. (2001) 'Enterprise resource planning systems research: an annotated bibliography', Communications for the Associations of Information Systems, Vol. 7, No. 8, pp.1-52.

Fan, X., Thompson, B. and Wang, L. (1999) 'Effects of sample size estimation methods and model specification on structural equation modeling fit indexes', Structural Equation Modeling, Vol. 6, No. 1, pp.56-83.

Fishbein, M. and Ajzen, I. (1975) Belief, Attitude, Intention and Behavior: An Introduction to Research and Theory, Addison-Wesley, Reading, MA.

Fornell, C. and Larcker, D. (1981) 'Structural equation models with unobservable variables and measurement error’, Journal of Marketing Research, Vol. 18, No. 1, pp.39-50. 
Gamal, A.M. (2009) 'An empirical analysis of ERP implementation in a developing country: toward a generic framework', International Journal of Enterprise Network Management, Vol. 3, No. 4, pp.309-331.

Gluck, M. (1996) 'Exploring the relationship between user satisfaction and relevance in information systems', Information Processing and Management, pp.89-104.

Goodhue, D.L. (1995) 'Understanding user evaluations of information systems', Management Science, Vol. 41, No. 12, pp.1827-1844.

Goodhue, D.L. (1998) 'Development and measurement validity of a task-technology fit instrument for user evaluations of information systems', Decision Sciences, Vol. 29, No. 1, pp.105-138.

Goodhue, D.L. and Thompson, R. (1995) 'Task-technology fit and individual performance', MIS Quarterly, Vol. 19, No. 2, pp.213-236.

Haines, J.M. and Goodhue, D.L. (2003) 'Implementing partner involvement and knowledge transfer in the context of ERP implementation', International Journal of Human-Computer Interaction, Vol. 16, No. 1, pp.23-38.

Hair, J.F., Anderson, R.E., Tatham, R.L. and Black, W.C. (1998) Multivariate Data Analysis with Readings, 5th ed., Macmillan, New York.

Holland, P.C., Light, B. and Kawalek, P. (1999) 'Beyond enterprise resource planning projects: innovative strategies for competitive advantage', Proceeding of the 7 th International Conference on Information Systems, Copenhagen, pp.288-301.

Holsapple, C.W. and Sena, M.P. (2005) 'ERP plans and decision-support benefits', Decision Support Systems, Vol. 38, No. 4, pp.575-590.

$\mathrm{Hu}$, L.T. and Bentler, P.M. (1999) 'Cutoff criteria for fit indexes in covariance structure analysis: conventional criteria versus new alternatives', Structural Equation Modeling, Vol. 6, No. 1, pp.1-55.

Hwang, Y. (2005) 'Investigating enterprise systems adoption: uncertainty avoidance, intrinsic motivation and the technology acceptance model', European Journal of Information Systems, pp.150-161.

Im, G. and Raven, A. (2003) 'Fit and social construction in knowledge management systems', The Annual European Conference on Information Systems, Naples, Italy, 16-21 June, Paper 61.

Irick, M.L. (2008) 'Task-technology fit and information systems effectiveness', Journal of Knowledge Management Practice, Vol. 9, No. 3, available at http://www.tlainc.com/ jkmpv9n308.htm.

Keil, M., Beranek, P.M. and Konsynski, B.R. (1995) 'Usefulness and ease of use: field study evidence regarding task considerations', Decision Support Systems, Vol. 13, No. 1, pp.75-91.

Kilmon, C.A., Fagen, M.H., Pandy, V. and Bett, T. (2008) 'Using the task technology fit model as a diagnostic tool for electronic medical records systems evaluation', Issues in Information Systems, Vol. 9, No. 2, pp.196-204.

King, W.R. and He, J. (2006) 'A meta-analysis of the technology acceptance model', Information and Management, Vol. 43, No. 6, pp.740-755.

Klaus, H., Roseman, M. and Gable, G.G. (2000) 'What is ERP?', Information Systems Frontiers, Vol. 2, No. 2, pp.141-161.

Klopping, I.M. and McKinney, E. (2004) 'Extending the technology acceptance model and the task-technology fit model to consumer e-commerce', Information Technology, Learning and Performance Journal, Vol. 22, No. 1, pp.35-48.

Kuo, R-Z. and Lee, G-G (2011) 'Knowledge management system adoption: exploring the effects of empowering leadership, task-technology fit and compatibility', Behaviour and Information Technology, Vol. 30, No. 1, pp.113-129.

Lee, Y., Kozar, K.A. and Larsen, K.R.T. (2003) 'The technology acceptance model: past, present and future', Communications of the AIS, Vol. 12, No. 5, pp.752-780. 
Madapusi, A. and D'Souza, D. (2012) 'The influence of ERP system implementation on the operational performance of an organization', International Journal of Information Management, Vol. 32, No. 1, pp.24-34.

Markus, L.M. and Keil, M. (1994) 'If we build it, they will come: designing information systems that people want to use', Sloan Management Review, Vol. 35, pp.11-25.

Maruping, L.M. and Agarwal, R. (2004) 'Managing team interpersonal processes through technology: a task-technology fit perspective', The Journal of Applied Psychology, Vol. 89, No. 6, pp.975-990.

Mathieson, K. (1991) 'Predicting user intentions: comparing the technology acceptance model with the theory of planned behavior', Information Systems Research, Vol. 2, No. 3, pp.173-191.

Nah, F.F., Tan, X. and Teh, S.H. (2004) 'An empirical investigation on end-users' acceptance of enterprise systems', Information Resources Management Journal, Vol. 3, pp.32-53.

Nunnally, J.C. (1978) Psychometric Theory, McGraw-Hill Book Company, New York.

Nunnally, J.C. and Bernstein, I.H. (1994) Psychometric Theory, 3rd ed., McGraw-Hill, New York.

Osei-Bryson, K-M., Dong, L. and Ngwenyama, O. (2008) 'Exploring managerial factors affecting ERP implementation: an investigation of the Klein-Sorra model using regression splines', Information Systems Journal, Vol. 18, No. 5, pp.499-527.

Polancic, G., Hericko, M. and Pavlic, L. (2011) 'Developers' perceptions of object-oriented frameworks - an investigation into the impact of technological and individual characteristics', Computers in Human Behavior, Vol. 27, No. 2, pp.730-740.

Rao, S. (2000) 'Enterprise resource planning: business needs and technologies', Vol. 100, No. 2, pp.81-88.

Roca, J.C., Chiu, C-M. and Martinez, F.J. (2006) 'Understanding e-learning continuance intention: an extension of the technology acceptance model', International Journal of Human-Computer Studies, Vol. 64, No. 8, pp.683-696.

Roger, E.M. (1995) Diffusion of Innovations, Free Press, New York.

Rolland, C. and Prakash, N. (2000) 'Bridging the gap between organizational needs and ERP functionality', Requirements Engineering, Vol. 5, No. 3, pp.180-193.

Shevlin, M. and Miles, J.N.V. (1998) 'Effects of sample size, model specification and factor loadings on the GFI in confirmatory factor analysis', Personality and Individual Differences, Vol. 25, No. 1, pp.85-90.

Shih, Y-Y. (2006) 'The effect of computer self-efficacy on enterprise resource planning usage', Behaviour and Information Technology, Vol. 25, No. 5, pp.407-411.

Shih, Y-Y. and Chen, C-Y. (2011) 'The study of behavioral intention for mobile commerce: via integrated model of TAM and TTF', Quality and Quantity, Online first, 30 August.

Shih, Y-Y. and Huang, S-S. (2009) 'The actual usage of ERP systems: an extended technology acceptance perspective', Journal of Research and Practice in Information Technology, Vol. 41, No. 3, pp.263-276.

Smyth, R.W. (2001) 'Challenges to successful ERP use (research in progress), global co-operation in the new millennium', The 9th European Conference on Information Systems, Bled, Slovenia, 27-29 June, pp.1227-1231.

Soh, C., Kien, S.S. and Tay-yap, J. (2000) 'Enterprise resource planning: cultural fits and misfits: is ERP a universal solution?', Communications of the ACM, Vol. 43, No. 4, pp.47-51.

Steiger, J.H. (2007) 'Understanding the limitations of global fit assessment in structural equation modeling', Personality and Individual Differences, Vol. 42, No. 5, pp.893-898.

Strong, D.M., Dishaw, M.T. and Bandy, D.B. (2006) 'Extending task technology fit with computer self-efficacy', ACM SIGMIS Database, Vol. 37, Nos. 2-3, pp.96-107.

Sun, J., Ke, O. and Cheng, Y. (2007) 'Study of consumer acceptance in e-commerce by integrating technology acceptance model with task-technology fit model', Proceeding for the International Conference on Wireless Communications Networking and Mobile Computing, 21-25 September, Shanghai, China, pp.3621-3624. 
Sun, Y., Bhattacherjee, A. and Ma, Q. (2009) 'Extending technology usage to work settings: the role of perceived work compatibility in ERP implementation', Information and Management, Vol. 46, No. 6, pp.351-356.

Tabachnick, B.G. and Fidell, L.S. (2007) Using Multivariate Statistics, 5th ed., Allyn and Bacon, New York.

Taylor, S. and Todd, P.A. (1995) 'Understanding information technology usage: a test of competing models', Information Systems Research, Vol. 6, No. 2, pp.144-176.

Tsai, W-H., Shaw, M.J., Fan, Y-W., Liu, J-Y., Lee, K-C. and Chen, H-C. (2011) 'An empirical investigation of the impacts of internal external facilitators on the project success of ERP: a structural equation modeling', Decision Support Systems, Vol. 50, No. 2, pp.480-490.

Usoro, A., Shoyelu, S. and Kuofie, M. (2010) 'Task-technology fit and technology acceptance models applicability to e-tourism', Journal of Economic Development, Management, IT, Finance and Marketing, Vol. 2, No. 1, pp.1-32.

Venkatesh, V. (2000) 'Determinants of perceived ease of use: integrating control, intrinsic motivation and emotion into the technology acceptance model', Information Systems Research, Vol. 11, No. 4, pp.342-365.

Venkatesh, V. and Davis, F.D. (1996) 'A model of the antecedents of perceived ease of use: development and test', Decision Science, Vol. 27, No. 3, pp.451-481.

Venkatesh, V. and Davis, F.D. (2000) 'A theoretical extension of the technology acceptance model: four longitudinal field studies', Management Science, Vol. 46, No. 2, pp.186-204.

Venkatesh, V. and Morris, M.G. (2000) 'Why don't men ever stop to ask for directions? gender, social influence and their role in technology acceptance and usage behavior', MIS Quarterly, Vol. 24, No. 1, pp.115-139.

Wang, Y.S., Wang, Y.M., Lin, H.H. and Tang T.I. (2003) 'Determinants of user acceptance of internet banking: an empirical study', International journal of Service Industry Management, Vol. 14, No. 5, pp.501-519.

Wells, J. and Palmer, J.W. (2004) 'Experiential fit: applying task-technology fit theory to experiential consumer tasks', Proceedings of the Tenth Americas Conference on Information Systems, August 2004, New York.

Wheaton, B., Muthen, B., Alwin, D.F. and Summers, G. (1977) 'Assessing reliability and stability in panel models', Sociological Methodology, Vol. 8, No. 1, pp.84-136.

Willis, T.H. and Willis-Brown, A.H. (2002) 'Extending the value of ERP', Industrial Management \& Data Systems, Vol. 102, No. 1, pp.35-38.

Wu, J.H. and Wang, Y.M. (2006) 'Measuring ERP success: the ultimate users view', International Journal of Operations and Production Management, Vol. 26, No. 8, pp.882-903.

$\mathrm{Wu}$, J.H., Chen, Y.C. and Lin, L.M. (2007) 'Empirical evaluation of the revised end user computing acceptance model', Computers in Human Behavior, pp.162-174.

Yeh, T.M., Yang, C.C. and Lin, W.T. (2007) 'Service quality and ERP implementation: a conceptual and empirical study of semiconductor-related industries in Taiwan', Computers in Industry, Vol. 58, Nos. 8-9, pp.844-854.

Yen, D.C., Wu, C-S., Cheng, F-F. and Huang, Y-W. (2010) Computers in Human Behavior, Vol. 26, No. 5, pp.906-915.

Youngberg, E., Olen, D. and Hauser, K. (2009) 'Determinants of professionally autonomous end-user acceptance in an enterprise resource planning systems environment', International Journal of Information Management, Vol. 29, No. 2, pp.138-144.

Zhang, H., Feng, L. and Archer, N. (2007) 'Empirical research based on TAM acceptance of mobile homecare systems', Proceeding in International conference on Wireless Communications, Networking and Mobile Computing, WiCom 2007, 21-25 September, Shanghai, China, pp.3143-3146.

Zhou, T., Lu, Y. and Wang, B. (2010) 'Integrating TTF and UTAUT to explain mobile banking user adoption', Computers in Human Behavior, Vol. 26, No. 4, pp.760-767. 